\title{
Identification of the best ovitrap installation sites for gravid Aedes (Stegomyia) aegypti in residences in Mirassol, state of São Paulo, Brazil
}

\author{
Margareth Regina Dibo/+ , Francisco Chiaravalloti-Neto/*, Marcos Battigaglia, \\ Adriano Mondini*, Eliane A Favaro*, Angelita AC Barbosa*, Carmen M Glasser
}

\author{
Superintendência de Controle de Endemias, Av. Philadelpho Manuel Gouveia Netto 3101, $3^{\circ}$ andar, 15060-040 \\ São José do Rio Preto, SP, Brasil *Faculdade de Medicina de São José do Rio Preto, São José do Rio Preto, SP, Brasil
}

This study aimed at identifying the best ovitrap installation sites for gravid Aedes aegypti in Mirassol, state of São Paulo, Brazil. Ovitraps were installed in ten houses per block over ten blocks. Four ovitraps were placed per residence, one in the bedroom, one in the living room, and two outdoors with one in a sheltered area and one in an outside site. Each week for eleven weeks, visits were made to examine the ovitraps and to change the paddles used for egg-laying. Eggs were analyzed according to the trap location. The results showed that the outdoor sites received significantly more oviposition than indoor sites. Additionally, in respect to the outdoor sites, the outside site received significantly more oviposition than the sheltered site. A strong correlation was observed between positive traps and egg numbers. The results are discussed with respect to the best installation site of the traps and their implications in surveillance and control of dengue vectors.

Key words: Aedes aegypti - ovitrap - installation site - Brazil

Dengue is a public health problem in the majority of tropical countries, where the climatic conditions favor the proliferation of Aedes (Stegomyia) aegypti, the main vector of the disease. In Brazil, the historical series showed a growing tendency in the incidence of the disease with a peak in 2002 and an increase in the rate of the hemorrhagic form. The state of São Paulo, Brazil, presented a similar tendency, with the greatest epidemic seen in 2001 with 51,248 cases (MS 2002).

Ae. aegypti is a domesticated species, whose life along side man is favored by the utilization of containers in residences suitable for breeding containers for the immature forms of culicid (Pereira 2001). The vector control strategy is centered on the reduction of potential breeding containers by the involvement of vector control personnel, of several public administration sectors, of productive sectors that indirectly contribute to the increased number of breeding containers and of the community.

Chemical control actions are only performed in dengue transmission situations (MS 2001). The routinely employed method to monitor Ae. aegypti population in Vector Control Program of the state of São Paulo is larval survey in potential breeding containers, which enables the attainment of entomological indicators such as the Premise, Container and Breteau Indexes (Breteau 1954, Gomes 1998). In non-infected municipalities this Program recommends the use of larvitraps, mat-black containers (sections of tires) containing 1 liter of water that are

Financial support: Fapesp

${ }^{+}$Corresponding author. E-mail: mrdibo@yahoo.com.br Received 29 July 2004

Accepted 4 May 2005 checked on a weekly basis, aiming at detecting foci of $A e$. aegypti (SES 2002).

Another method available for mosquito detection and monitoring is the use of ovitraps. Fay and Perry (1965) described the ovitrap, which was improved by Fay and Eliason (1966). It consists of a black container that is partially filled with tap water holding a vertical wooden paddle with one rough side. Fay and Eliason (1966) compared the ovitrap technique with a larval survey and concluded that both methods are complementary and that the oviposition trap is sensitive, fast, and economic to determine the presence of egg-laying females of Ae. aegypti.

In a comparative efficiency study of the ovitrap and larvitrap to detect Ae (Stg.) albopictus performed by Marques et al. (1993) in the state of São Paulo, ovitraps were more efficient even in the presence of natural breeding containers.

A study made in Bahia, Brazil, comparing a larval survey with ovitraps to detect and monitor Ae. aegypti, demonstrated that the trap was more sensitive for the detection of this insect, as well as being a cheaper method and operationally viable, with its utilization being preferred for vectorial surveillance (Braga et al. 2000).

Rawlins et al. (1998) compared the larval monitoring method with the presence of eggs in ovitraps in Trinidad and confirmed that the traps were significantly more sensitive. These authors recommended changes in the monitoring strategy of Ae. aegypti with the employment of traps in Caribbean cities.

Oviposition traps have been designated as a surveillance tool (Focks 2003) and for controlling the Ae. aegypti vector (Cheng et al. 1982, Zeichner \& Perich 1999). To improve the use of these traps in vector surveillance and control strategies, a better understanding of the behavior of Ae. aegypti is necessary. 
The aims of this study were to determine the oviposition behavior of Ae. aegypti in relation to site preferences within residences; to evaluate if there was a correlation between positive traps and egg numbers; to obtain an expected proportion of Ae. aegypti eggs on paddles.

\section{MATERIALS AND METHODS}

The municipality of Mirassol is located at $20^{\circ} 25^{\prime} \mathrm{S}$ $51^{\circ} 21^{\prime} \mathrm{W}$, in the state of São Paulo, Brazil. The climate is characterized as subtropical with two distinct seasons, a rainy season between November and April and a cooler dry season between May and October (Secretaria de Agricultura do Estado de São Paulo, unpublished data).

The town became infested with the Ae. aegypti mosquito in 1987. Ae. aegypti and Ae. albopictus infestation levels determined prior to this study showed a Breteau Index (the number of breeding containers with larvae of Ae. aegypti and/or Ae. albopictus multiplied by $100 \mathrm{di}-$ vided by the total number of houses inspected) (Breteau 1954) of 14.3 in January 2001 and 9.9 in February 2002 (Superintendência de Controle de Endemias, unpublished data).

The first reported transmission of dengue occurred in 1993 with an incidence coefficient of 67 cases per 100,000 inhabitants. In the following years, dengue became endemic. The highest incidence coefficient occurred in 2001, reaching 3351 cases per 100,000 inhabitants, one of the highest rates recorded in the state of São Paulo for that year (Centro de Vigilância Epidemiológica, unpublished data).

An area comprising 25 blocks with uniform one-floor houses was selected in Mirassol. Of these, 10 blocks were utilized for the installation of ovitraps. This area plus the 29 neighboring blocks, which had similar homogeneous characteristics, were used to measure the larval density before the initiation of the study (the first two weeks of September 2002) and after the end of the trial period (last 10 days of December 2002). This was achieved by systematically surveying all the blocks visiting alternate houses.

With the intention of installing traps in 10 houses in each of the 10 selected blocks, a total of 15 possible houses were randomly chosen per block. After explaining the idea of the experiment to the occupants, the first 10 houses where permission to install the traps was obtained, were included in the study.

The ovitraps consisted of 1 liter black plastic pots filled with $500 \mathrm{ml}$ of tap water. The oviposition substrate was a wooden paddle measuring $12.5 \mathrm{~cm}$ by $2 \mathrm{~cm}$ placed inside the pot. These were installed in the houses from 30th September to 4th October 2002. The trial period began on 7th October and finished on 20th December 2002.

Two traps were installed indoors, one in the bedroom and the other in the living room. Another two were placed outdoors, one protected from rain in a veranda or service area, the sheltered site, and one exposed to the weather, under leaves on tree branches or in bushes, at the front, side or back of the house, the outside site. Indoors, the oviposition traps were installed on bookcases, bed-side tables, chests of drawers, television stands, that is, places that allowed the traps to be hidden from view (from children and animals) behind pictures, books, images of saints, pots of artificial flowers, etc. In the sheltered site, the traps were installed in plant vases, places that allow them to remain out of sight too. All these places were preferably at heights from 0.5 to $1 \mathrm{~m}$. In order to maintain the same pattern, the outdoor traps were installed at about the same height in shrubs and in tree branches. The paddle of each ovitrap was removed every 7 days on the same day of the week.

The collected paddles were labeled and put to dry at room temperature for $24 \mathrm{~h}$. The paddles were analyzed by means of an stereo microscope and the eggs were counted with a manual counter. These paddles were kept in the laboratory for one week. A weekly random selection of 70 paddles was made proportional to the numbers of positive traps in relation to the different installation sites (bedroom, living room, sheltered or outside). To calculate the sample size we took into account: the maximum size of the population (400 paddles with eggs per week), an expected frequency of $94 \%$ of eggs being Ae. aegypti calculated from our previous experiments, a sample error of $5 \%$, and a confidence interval of $95 \%$ (95\% CI). The minimum expected sample fraction, if eggs were found on all the paddles in a specific week, was 0.18 (70 in 400). Weekly, 70 paddles were placed in individual containers of water for egg-hatching. The larvae were fed with fish food until they reached the third stage of development and they were identified by microscopy using taxonomic keys (Consoli \& Lourenço-de-Oliveira 1998).

The measurements of larval density performed before and after trap installation supplied information about the number of positive breeding containers for Ae. aegypti and Ae. albopictus in the study area. From these measurements, the Breteau Indexes (BI) for each species (Breteau 1954) and their respective 95\% CI (Altman 1999) were calculated. The study of the behavior of Ae. aegypti in respect to the location of the oviposition was an evaluation of the positivity (number of paddles with eggs multiplied by 100 divided by the total number of paddles) and of the number of eggs collected in traps. Positivity was calculated for the set of data obtained over 11 weeks for the following trap sites: indoors, outdoors, bedroom, living room, sheltered, and outside. The following comparisons were made using the chi-squared test to calculate the statistical significance: indoors and outdoors; bedroom and living room; sheltered, and outside (Altman 1999). The positivities, with their respective $95 \%$ CI, were also calculated for individual weeks according to the ovitrap installation sites.

The numbers of eggs were calculated for the same trap installation sites mentioned above summing the numbers of eggs over 11 weeks from each of the houses included in the study. These numbers were transformed using the square root to guarantee a close approximation to the normal and the results were compared for the following trap installation sites: indoors and outdoors; bedroom and living room; sheltered, and outside. Statistical significance was assessed using the two-tailed Student ttest (Altman 1999). 
The mean numbers of eggs (number of eggs collected divided by the total number of houses) were calculated for the total trial period and also for individual weeks according to the ovitrap installation sites. The mean numbers per week are presented with the respective $95 \%$ CI.

To evaluate the existence of a correlation between the positivity and the mean numbers of eggs in any particular week for the different sites studied, Spearman coefficients and the respective p-values were calculated. This coefficient was utilized to evaluate the correlation between the positivity and the mean egg numbers of the traps in respect to rainfall and minimum and maximum temperatures (Altman 1999).

On analyzing the number of larvae and species from the sample of 70 paddles randomly chosen every week, for hatching, the expected proportions of Ae. aegypti and Ae. albopictus on any paddle together with the respective $95 \%$ CI were estimated (Altman 1999).

In the cases that the statistical tests were performed, results with p-values of less than $5 \%$ were considered significant.

\section{RESULTS}

In the analysis of the initial infestation performed during the dry season, the BI for Ae. aegypti was estimated at 2.8 (95\% CI: 1.1-4.6); no Ae. albopictus larvae were collected in this study. After removal of the ovitraps, another estimation of infestation levels was made in the rainy season, giving BIs of 9.8 (95\% CI: 6.2-13.4) for Ae. aegypti and 0.4 (95\% CI: 0.0-0.7) for Ae. albopictus. For the first measurement of the BI, 458 residences were inspected and for the second measurement, 531 residences were included.

In the 100 residences with traps a total of 4400 paddles were obtained of which $38.6 \%$ (95\% IC: $37.1-40.0$ ) were positive for eggs. The positivity of the outdoor traps was significantly greater than the indoor traps (Table I). For the outdoor sites, the positivity of the outside site was significantly greater than the sheltered site (Table I). For the indoor sites however, there were no significant differences between the bedroom and the living room sites (Table I).

Taking into account the entire 11 -week period, the numbers of eggs collected in the outdoor traps were significantly higher than the indoor traps (Table I). The numbers of eggs collected in the outside site were significantly higher than the sheltered site (Table I). The numbers of eggs collected in the bedroom and the living room did not give any significant difference (Table I).

The positivities presented in Tables II and III show the mean number of eggs of the ovitraps according to the week and the installation site with respective $95 \%$ CI. Table IV presents the Spearman coefficients evaluating the relationship between the positivity and the mean numbers of eggs over the weeks at the different trap sites.

Of a total of 1697 paddles with eggs, 783 (sample fraction $=0.46$ ) were flooded for egg hatching. Of the total of 135,018 eggs collected, 54,245 were flooded for hatching, from which 15,631 larvae emerged, which represent a hatching rate of $28.8 \%$. Of the total of paddles flooded, hatching occurred in $690(88.1 \%)$. The expected proportion of Ae. aegypti eggs on any specific paddle was calculated at

TABLE I

Positivity and the mean numbers of eggs according to ovitrap installation sites, Mirassol, state of São Paulo, Brazil, 2002

\begin{tabular}{lcccc}
\hline Site & Positivity $(\%)$ & P-value $($ Chi-squared test) & Mean number of eggs & P-value (Student t-test) \\
\hline Outdoors & 52.9 & $0.0000^{a}$ & 101.9 & $0.0000^{a}$ \\
Indoors & 24.2 & 20.8 & 9.8 & 0.4347 \\
Bedroom & 23.7 & 0.06188 & 72.2 & $0.0000^{a}$ \\
Living room & 24.7 & $11.0^{a}$ & 72.2 & \\
Outside & 64.0 & $0.0000^{a}$ & & \\
Sheltered & 41.8 & 29.7 & & \\
\hline
\end{tabular}

a: significant results

TABLE II

Positivity (\%) according to ovitrap installation sites and weeks, Mirassol, state of São Paulo, Brazil, 2002

\begin{tabular}{lcccr}
\hline & \multicolumn{4}{c}{ Site $(95 \%$ confidence interval) } \\
\cline { 2 - 5 } Week & Bedroom & Living room & Sheltered & Outside \\
\hline 1 & $2.0(0.2-7.0)$ & $3.0(0.6-8.5)$ & $19.0(11.8-28.1)$ & $24.0(16.0-33.6)$ \\
2 & $1.0(0.0-5.4)$ & $2.0(0.2-7.0)$ & $14.0(7.9-22.4)$ & $38.0(28.4-48.3)$ \\
3 & $13.0(7.0-21.0)$ & $12.0(6.4-20.0)$ & $30.0(21.2-40.0)$ & $51.0(40.8-61.1)$ \\
4 & $30.0(21.2-40.0)$ & $22.0(14.3-31.4)$ & $43.0(33.1-53.3)$ & $57.0(46.7-66.9)$ \\
5 & $20.0(12.7-29.2)$ & $21.0(14.5-30.3)$ & $30.0(21.2-40.0)$ & $65.0(54.8-74.3)$ \\
6 & $26.0(17.7-35.7)$ & $26.0(17.7-35.7)$ & $43.0(33.1-58.3)$ & $58.0(47.7-67.8)$ \\
7 & $23.0(15.2-32.5)$ & $35.0(25.7-45.2)$ & $50.0(39.8-60.1)$ & $75.0(65.0-83.1)$ \\
8 & $33.0(23.9-43.1)$ & $37.0(27.6-47.2)$ & $60.0(49.7-69.7)$ & $83.0(74.2-90.0)$ \\
9 & $22.0(14.3-31.4)$ & $24.0(16.0-33.6)$ & $42.0(32.2-52.3)$ & $74.0(64.3-82.3)$ \\
10 & $33.0(23.9-43.1)$ & $32.0(23.0-42.1)$ & $53.0(42.8-63.1)$ & $85.0(76.5-91.4)$ \\
11 & $58.0(47.7-67.8)$ & $58.0(47.7-67.8)$ & $68.0(57.9-77.0)$ & $94.0(87.4-97.8)$ \\
\hline
\end{tabular}


TABLE III

Mean numbers of eggs according to ovitrap installation sites and weeks, Mirassol, state of São Paulo, Brazil, 2002

\begin{tabular}{|c|c|c|c|c|}
\hline \multirow[b]{2}{*}{ Week } & \multicolumn{4}{|c|}{ Site $(95 \%$ confidence interval) } \\
\hline & Bedroom & Living room & Sheltered & Outside \\
\hline 1 & $0.2(0.0-0.5)$ & $0.4(0.0-0.9)$ & $3.1(1.4-4.8)$ & $10.4(5.5-15.4)$ \\
\hline 2 & $0.1(0.0-0.2)$ & $1.0(0.0-2.7)$ & $5.6(1.3-9.9)$ & $17.8(10.8-24.8)$ \\
\hline 3 & $3.3(1.2-5.5)$ & $2.1(0.5-3.7)$ & $19.0(10.0-28.0)$ & $43.2(26.6-59.8)$ \\
\hline 4 & $7.8(4.0-11.6)$ & $7.8(3.1-12.5)$ & $20.4(13.0-27.8)$ & $34.0(21.6-46.4)$ \\
\hline 5 & $4.7(1.4-8.0)$ & $15.7(6.2-25.2)$ & $24.3(13.4-35.2)$ & $60.8(44.3-77.3)$ \\
\hline 6 & $7.5(3.6-11.5)$ & $10.0(4.7-15.4)$ & $32.0(19.5-44.5)$ & $59.0(40.1-77.9)$ \\
\hline 7 & $26.2(6.5-45.8)$ & $23.9(14.3-33.6)$ & $54.5(35.4-73.7)$ & $125.3(94.8-155.8)$ \\
\hline 8 & $16.3(6.3-26.3)$ & $14.6(7.7-27.5)$ & $60.7(42.1-79.3)$ & $101.6(79.9-123.3)$ \\
\hline 9 & $7.4(3.5-11.2)$ & $8.0(3.4-12.6)$ & $25.9(15.2-36.6)$ & $81.5(61.4-101.5)$ \\
\hline 10 & $14.9(7.9-21.9)$ & $11.3(5.5-17.0)$ & $43.3(28.3-58.4)$ & $121.6(93.5-149.8)$ \\
\hline 11 & $19.7(12.2-27.2)$ & $22.8(13.6-31.9)$ & $37.7(20.9-54.5)$ & $139.0(93.3-184.7)$ \\
\hline
\end{tabular}

\section{TABLE IV}

Spearman coefficients $(\rho)$ and the p-values for positivity and mean numbers of eggs according to ovitrap installation sites, Mirassol, state of São Paulo, Brazil, 2002

\begin{tabular}{lcc}
\hline Site & $\rho$ & p-value \\
\hline Bedroom & 0.8611 & 0.0007 \\
Living room & 0.7909 & 0.0037 \\
Sheltered & 0.8813 & 0.0003 \\
Outside & 0.9636 & 0.0000 \\
\hline
\end{tabular}

99.2\% (95\% CI: 98.9-99.5) and for Ae. albopictus it was $0.8 \%$ (95\% CI: 0.5-1.1).

During the period of the trial, there was a rainfall of 58 $\mathrm{mm}$ in October, $135 \mathrm{~mm}$ in November, and $149 \mathrm{~mm}$ in December, normal figures for these months of the year. The Spearman correlation coefficients calculated between the positivity and the mean numbers of eggs of the traps in respect to the rainfall and the minimum and maximum temperatures did not present significant results (Secretaria da Agricultura do Estado de São Paulo, unpublished data, Altman 1999).

\section{DISCUSSION}

Although there was a competition between the ovitraps and other existing breeding containers, some traps became positive within the first week, that is, during the dry season. Thus, this method was confirmed to be efficient in detecting vectors of Aedes (Stg.), as has been described by Fay and Eliason (1966), Marques et al. (1993), and Braga et al. (2000).

An analysis of the data about the distribution of positive traps and the eggs deposited demonstrated that more oviposition occurred in the outdoor sites compared to indoors and the outside site received more oviposition than the sheltered site. Rezende et al. (1999) installed ovitraps in three municipalities in the following locations around houses: backyard, service area, veranda, side area, and garden. They obtained higher oviposition of Ae. aegypti in the backyard and service area.

The high Spearman coefficients between positivity and mean numbers of eggs indicate that one variable can pre- dict the other. Mogi et al. (1990) found a similar correlation between the average egg numbers and the positivity suggesting that the mean egg numbers per trap can be estimated without actually counting the eggs. From this they concluded that the method might be utilized to indicate when control actions should be initiated.

These results have important repercussions on the use of ovitraps as an entomological surveillance tool. Apart from the establishment of the outside site as the best site for their installation, the high correlation between the positivity and the egg numbers and the expected proportions of Ae. aegypti eggs of close to $100 \%$ on paddles may represent a significant simplification of this activity as well as an optimization of resources. In the region of São José do Rio Preto, with a great predominance of $A e$. aegypti in comparison to Ae. albopictus (ChiaravallotiNeto et al. 2002) and in other regions with similar characteristics the traps can be utilized without the necessity of actually counting the eggs or the necessity of hatching the eggs.

When identification of the existence of eggs is the most important activity, aggregation of techniques may improve the speed of data collection and decision making. One example is the use of palmtop computers in the field to register the positivity of each trap with immediate updating of the database. This together with a Geographic Information System (GIS), where the location of the traps are georeferenced using vectorial maps if they exist, or using Global Positioning Systems (GPS) may quickly provide information about the distribution of the vector and serve as a stratification tool in control measures (Ai-leen \& Song 2000).

Barata et al. (2001) captured mosquitoes using Nasci aspirators in residences and confirmed that $87.3 \%$ of female Ae. aegypti were caught indoors. Although inside the house seems to correspond to the ideal environment for shelter and blood feeding this current study showed that, even with the availability of ovitraps indoors (in the bedroom and living room), the majority of gravid females preferred to deposit eggs outdoors. This behavior suggests that females may enter the houses for blood feeding and resting and leave the houses to deposit their eggs, a question that requires further investigation. 
These results have repercussions on vector control strategies. If the main interest is to eliminate adult mosquitoes to interrupt the transmission of dengue fever, actions inside residences should be prioritized. In Brazil when there is transmission of dengue, many municipalities still use chemical control of adult Ae. aegypti mosquitoes using ultra low volume ground applications of insecticide sprayed from vehicles that circulate the city streets (Barata et al. 2001). As physical barriers such as trees and closed doors and windows restrict the entrance of the product to enter inside residences, many of the mosquitoes are not affected which greatly reduces the effectiveness of this measure (Reiter et al. 1990). This current study and others cited might serve as a parameter for changes in relation to this activity.

If the interest is preventative, aiming at eliminating the immature forms of the mosquitoes, the principal actions should be concentrated outdoor. In the region of São José do Rio Preto one of the main reasons that members of the population refuse to participate in programs to eliminate breeding containers is the necessity of endemic control agents to enter the house (Superintendência de Controle de Endemias, unpublished data), a situation that must exist in other regions of the country. The establishment of the outdoors as the favored oviposition site may restrict the necessity of control activities of the immature forms to this environment, increasing the acceptability of these measures by the population and optimizing resources.

\section{ACKNOWLEDGEMENTS}

To José A Cordeiro, David A Hewitt, Jean F Carmo, Denilson F Peralta, Darlene P Gonçalves, Marlene CG Souza, Rita CRM Preto, Beatriz AC Beline, Perpétua MM Sereno, Neuza FA Santana, Marcelo D Papa, Dora Defende, and the fieldwork teams of the Superintendência de Controle de Endemias.

\section{REFERENCES}

Ai-leen GT, Song RJ 2000. The use of GIS in ovitrap monitoring for dengue control in Singapore. Dengue Bull 24: 110116.

Altman DG 1999. Practical Statistics for Medical Research, Chapman \& Hall/CRC, Boca Raton, FL.

Barata EAMF, Costa AIP, Chiaravalloti-Neto F, Glasser CM, Barata JMS, Natal D 2001. População de Aedes aegypti (L.) em área endêmica de dengue, sudeste do Brasil. Rev Saúde Públ 35: 237-242.

Braga IA, Gomes AC, Nelson M, Mello RCG, Bergamaschi DP, Souza JMP 2000. Comparação entre pesquisa larvária e armadilha de oviposição, para detecção de Aedes aegypti. Rev Bras Med Trop 33: 347-353.

Breteau H 1954. La fièvre jaune en Afrique-Occidentale Française. Bull WHO 11: 453-481.

Cheng ML, Ho BC, Bartnett RE, Goodwin N 1982. Role of a modified ovitrap in the control of Aedes aegypti in Houston, Texas, USA. Bull WHO 60: 291-296.

Chiaravalloti-Neto F, Dibo MR, Barbosa AAC, Battigaglia M 2002. Aedes albopictus (S) na região de São José do Rio Preto, SP: estudo de sua infestação em área já ocupada pelo Aedes aegypti e discussão de seu papel como possível vetor de dengue e febre amarela. Rev Soc Bras Med Trop 35: 351357.

Consoli RAGB, Lourenço-de-Oliveira R 1998. Principais Mosquitos de Importância Sanitária no Brasil, Fiocruz, Rio de Janeiro, $225 \mathrm{pp}$.

Fay RW, Eliason DA 1966. A preferred oviposition site as a surveillance method for Aedes aegypti. Moq News 26: 531535.

Fay RW, Perry AS 1965. Laboratory studies of ovipositional preferences of Aedes aegypti. Mosq News 25: 276-281.

Focks DA 2003. A Review of Entomological Sampling Methods and Indicators for Dengue Vectors, World Health Organization, Gainsville, $40 \mathrm{pp}$.

Gomes AC 1998. Medidas dos níveis de infestação urbana para Aedes (Stegomyia) aegypti e Aedes (Stegomyia) albopictus em programa de vigilância entomológica. IESUS 7: 49-57. Marques CCA, Marques GRAM, Brito M, Santos Neto LG, Ishibashi VC, Gomes FA 1993. Estudo comparativo de eficácia de larvitrampas e ovitrampas para vigilância de vetores de dengue e febre amarela. Rev Saúde Públ 27: 237241.

Mogi M, Choochote W, Khamboonruang C, Swanpanit P 1990. Applicability of presence-absence sampling for ovitrap surveillance of Aedes (Diptera: Culicidae) in Chiang Mai, Northern Thailand. J Med Entomol 27: 509-514.

MS 2001. Ministério da Saúde. Fundação Nacional de Saúde, Plano de Intensificação das Ações de Controle do Dengue, Ministério da Saúde, Brasília, 25 pp.

MS 2002. Ministério da Saúde. Fundação Nacional de Saúde, Programa Nacional de Controle da Dengue, Ministério da Saúde, Brasília, 28 pp.

Pereira M 2001. Produtuvidade de Habitats Larvários de Aedes aegypti em Santos, Estado de São Paulo, Thesis, Faculdade de Saúde Pública, USP, São Paulo, 93 pp.

Rawlins SC, Martinez R, Wiltshire S, Legall G 1998. A comparison of surveillance systems for the dengue vector Aedes aegypti in Port of Spain, Trinidad. J Am Mosq Control Assoc 14: 131-136.

Reiter P, Nelson MJ, Nathan MB, Eliason DA, Amador MA, Zimmerman RH, Mazzari M, Rodriguez H, Martinez C, Domingo J, Coelho D 1990. An Evaluation of the Efficacy of Vehicle-dispensed Ultra Low Volume (ULV) Malathion for the Control of Aedes aegypti in Urban Areas of Maracay, Venezuela, Puerto Rico, Centers for Disease Control, Atlanta, 99 pp.

Resende M, Lamounier MA, Roque RA, Duarte RN, Ivo ES, Nogueira R, Eiras AE 1999. Avaliação de locais de instalação de ovitrampas em residências e viabilidade de ovos de Aedes aegypti e Aedes albopictus nos municípios de Juiz de Fora, Pedro Leopoldo e Vespasiano (MG) (Resumo). Anais do XVI Congresso Brasileiro de Parasitologia, Poços de Caldas, p. 78 .

SES 2002. Secretaria de Estado da Saúde. Superintendência de Controle de Endemias, Normas e Recomendações Técnicas para Vigilância e Controle do Aedes aegypti no Estado de São Paulo, Secretaria de Estado de Saúde, São Paulo, 70 pp.

Zeichner BC, Perich MJ 1999. Laboratory testing of a lethal ovitrap for Aedes aegypti. Med Veter Entomol 13: 234-238. 
